NBER WORKING PAPER SERIES

\title{
EU, NAFTA, AND ASIAN RESPONSES: \\ A PERSPECTIVE FROM THE CALCULUS OF PARTICIPATION
}

\author{
Junichi Goto \\ Koichi Hamada
}

Working Paper 5325

\author{
NATIONAL BUREAU OF ECONOMIC RESEARCH \\ 1050 Massachusetts Avenue \\ Cambridge, MA 02138 \\ October 1995
}

This paper was prepared for the 1995 NBER East Asian Seminar on Economics, June 15-17, 1995, Seoul, Korea, and is part of NBER's research program in International Trade and Investment. Any opinions expressed are those of the authors and not those of the National Bureau of Economic Research.

(c) 1995 by Junichi Goto and Koichi Hamada. All rights reserved. Short sections of text, not to exceed two paragraphs, may be quoted without explicit permission provided that full credit, including $\odot$ notice, is given to the source. 


\section{EU, NAFTA, AND ASIAN RESPONSES:}

A PERSPECTIVE FROM THE CALCULUS OF PARTICIPATION

\section{ABSTRACT}

This paper assesses the economic conditions for Asian countries to cope with the formation of EU and NAFTA. Is it desirable for them to form their own trading area? And, if desirable, is it better to have a closed one like the EAEC or a more open one like the APEC? Relying on public economics and the calculus of participation combined with the DixitStiglitz-Krugman framework, we find the following: (i) the development of the EAEC by the leadership of Malaysia would be a natural response of Asian countries against two big blocs in the world, EU and NAFTA; (ii) it is natural for the United States to discourage this move because the formation of an economic bloc in Asia will have a negative economic impact on the non-Asian countries; (iii) it is natural for the U.S. to propose an opposing coalition like the APEC to nullify the possible economic impact of the EAEC; but (iv) perhaps the APEC will be a good roundabout way towards international free trade.

Junichi Goto

Research Institute for

Economics and Business

Kobe University

2-1 Rokkodai-cho

Nada-Ku, Kobe 617

JAPAN
Koichi Hamada

Economic Growth Center

Yale University

PO Box 208269

New Haven, CT 06520-8269 
Goto/Hamada

\section{Introduction}

It is safe to say that the Asia and West-Pacific area has been the most active, and the highest growing region in the world economy in the past ten years. It is a fermenting area on the globe. The Asia and West-Pacific area extends over a wide variety of regions, starting from the Oceania, the South Asia, the ASEAN countries, the NIEs, China and other Transitional Economies of Asia (TEA) and Japan. EU is a relatively compact area; the NAFTA, though it can potentially extend long north and south in the future, still do not have the spatial entity as the Asia-West Pacific area.

According to Nomura Research Institute (1989), in 1987 the combined GNP size of all West Pacific economies (excluding south Asia) was expected to approach $\$ 6.34$ trillion. This is comparable to the EC (with a GNP of $\$ 6.04$ trillion) and North America (with a GNP of $\$ 7.17$ trillion). It is expected that recent appreciation of the currencies of some West Pacific countries further increases the relative economic sizes of these countries. Thus these three regions have a similar economic size in the world economy.

In terms of growth rate the Asian performance has been remarkable. Table 1 shows the growth rate of GDP of the developing member countries (DMC) of the Asian Development Bank. As this table shows, on average these Asian and Pacific countries 
grows almost 8 percent through $1980^{\prime} \mathrm{s}$. Especially, China has shown double-digit growth rate in the $1980^{\prime} \mathrm{s}$, and her growth rate in recent years exceeds 13 percent. In addition to China, the growth rates of the NIEs and ASEAN countries are also high. In the past several years, the Philippines recorded relatively slow growth rates. But, we hear that in 1994 the Philippines experienced a remarkable growth rate.

Many countries in this area have diversity of ethnicity, religion, history, political systems, and economic mechanisms. The diversity is well illustrated in case of religion. Christianity is prevalent in Australia, New Zealand, and fairly influential in Korea. Catholic is dominant in the Philippines. Moslem is the main religion of Pakistan, Bangladesh, Malaysia, and Indonesia. Indeed, the Moslem population of Indonesia is the largest national figure in the world. In the other part of the world, Hinduism and Buddhism are influential. And ethic of Confucianism lies in the background ${ }^{1}$.

1 Morishima (1982) maintains that ethic of Confucianism played the same role as that of protestantism did in order to develop capitalism. However, his interpretation of Confucianism that emphasizes the hierarchical order between the superior and the subordinate seems to be somewhat conditioned by his navy experience in Japan, and to lack the recognition of various facets of confucianism. In one country the emphasis of Confucianism is on its liturgical aspect, and in another country Confucianism is conceived as the way to be successful in the bureaucracy and to invite family and friends to the government like the spoils system in the united states. 
TABLE 1

Growth Rate of GDP

(per cent per annum)

\begin{tabular}{|c|c|c|c|c|c|}
\hline & $\begin{array}{l}\text { Average } \\
1971-80\end{array}$ & $\begin{array}{l}\text { Average } \\
1981-90\end{array}$ & 1991 & 1992 & 1993 \\
\hline Newly Industrializing Economies & 9.0 & 8.3 & 7.4 & 5.5 & 5.7 \\
\hline Hong Kong & 9.3 & 7.2 & 4.1 & 5.3 & 5.5 \\
\hline Korea, Rep. of & 9.0 & 8.8 & 8.5 & 4.8 & 4.7 \\
\hline Singapore & 7.9 & 6.3 & 6.7 & 5.8 & 9.9 \\
\hline Taipei, China & 9.3 & 8.5 & 7.2 & 6.6 & 6.2 \\
\hline People's Rep. of China and Mongolia & 7.9 & 10.4 & 8.0 & 13.2 & 13.4 \\
\hline China, People's Rep. of & 7.9 & 10.4 & 8.0 & 13.2 & 13.4 \\
\hline Mongolia & 7.1 & 5.6 & -9.9 & -7.6 & -1.3 \\
\hline Southeast Asia & 7.4 & 6.1 & 6.4 & 6.1 & 6.4 \\
\hline Cambodia & - & - & 7.6 & 7.0 & 5.7 \\
\hline Indonesia & 7.7 & 5.5 & 6.9 & 6.4 & 6.5 \\
\hline Lao People's Democratic Rep. & - & - & 4.0 & 7.0 & 4.0 \\
\hline Malaysia & 7.8 & 5.2 & 8.7 & 7.8 & 8.0 \\
\hline Philippines & 6.0 & 1.0 & -0.5 & 0.1 & 1.7 \\
\hline Thailand & 7.9 & 7.9 & 8.1 & 7.6 & 7.8 \\
\hline Viet Nam, Socialists Rep. of & - & 7.1 & 6.0 & 8.3 & 8.0 \\
\hline South Asia & 4.0 & 5.7 & 2.1 & 4.5 & 3.8 \\
\hline Bangladesh & 5.8 & 4.1 & 3.4 & 4.2 & 4.5 \\
\hline Bhutan & - & 7.4 & 1.9 & 5.3 & 5.0 \\
\hline India & 3.7 & 5.8 & 1.2 & 4.0 & 3.8 \\
\hline Maldives & - & 12.1 & 7.6 & 6.3 & 6.1 \\
\hline Myanmar & 4.7 & -0.1 & -1.0 & 10.9 & 5.8 \\
\hline Nepal & 3.2 & 5.0 & 4.6 & 2.1 & 2.9 \\
\hline Pakistan & 5.2 & 6.2 & 5.6 & 7.7 & 3.0 \\
\hline Sri Lanka & 4.3 & 3.9 & 4.6 & 4.3 & 6.1 \\
\hline Pacific Islands & - & 1.2 & 6.6 & 6.4 & 10.1 \\
\hline Cook Islands & - & 5.8 & 7.0 & 11.0 & 1.2 \\
\hline Fiji & 4.3 & 1.7 & 0.7 & 2.9 & 1.8 \\
\hline Kiribati & - & -0.6 & 2.8 & 3.1 & 2.9 \\
\hline Marshall Islands & - & 10.1 & 0.6 & 0.1 & - \\
\hline Micronesia, Federated States of & 一 & - & - & - & - \\
\hline Papua New Guinea & - & 1.0 & 9.5 & 8.5 & 14.4 \\
\hline Solomon Islands & - & 3.4 & 3.2 & 8.2 & 6.0 \\
\hline Tonga & - & $\overline{1}$ & 5.8 & -3.7 & 0.0 \\
\hline Tuvalu & - & 13.4 & 11.4 & 8.9 & 8.7 \\
\hline Vanuatu & - & 1.6 & 3.5 & -0.1 & 2.0 \\
\hline Western Samoa & - & 1.0 & -1.6 & -4.2 & 4.8 \\
\hline Average for DMCs & 6.8 & 7.8 & 6.3 & 7.4 & 7.4 \\
\hline
\end{tabular}

Source: Asian Development Bank (1995) 
The association between growth and confucian thinking was a very appealing idea in the last decade when the NIEs and Japan were growing really fast. Given the remarkable growth record of many diverse Asian countries, now one wonder if confucianism is really the main driving force.

Political systems vary as well. Many NIEs were under dictatorship, and even now these countries have powerful central government. In post socialist countries or TEA the political systems are often close to dictatorial. In some countries human rights issues are criticized by developed nations. objectively speaking, history seems to tell that dictatorship does not necessarily obstruct high economic growth. We are not advocating dictatorship, of course, and we cannot attribute the cause of high growth of Asia West-Pacific area to dictatorial government. History gives important preconditions to these countries. The Philippines have the history of American colonial influence; South Asia countries, singapore, and Hong Kong were under the British colonial influence; and Korea and Taiwan were under the Japanese influence. It would be interesting to study how the ethnic, social and economic local system is interacted with the colonial legal, economic infrastructure. In the discussion of the formation of a free trade area in the South Asia, the fact should be noted that the South Asian countries used to form a single country when the colonial control of the Great Britain ended (Srinivasan 1994). 
Finally, most of these are now market economies. However, the degree of openness of these countries are also diverse. TEA countries are by definition in transition from the socialist economy to the market economy. The pleasant surprise in the Asian case is that these transitional economies have been doing well in average, and extremely well in some countries. In external trade, singapore and Hong Kong are free ports, pursuing free trade system and have been benefitted from it. other countries have some protectionistic elements. The revenue triangle of tax revenue is presented as Figure 1. The Figure indicates in what degree a country depend on the direct tax, indirect tax and trade related taxes like tariffs and levies. Thus it is difficult to single out a factor for the economic success of the Asia West-Pacific Region. At least one may notice, however, that all those countries are surrounded by the Pacific Ocean or the Indian Ocean and transportation by oceanic routes is available. Accordingly, and by other reasons, the degree of intraregional trade measured by the trade intensity index or the trade dependency index that is defined as the ratio of the sum of export and import to GNP is quite high (for details, see Goto and Hamada (1994), p.370 and p.374).

Now Asian countries have been watching the European Union and NAFTA carefully, and sometimes nervously. As was already analyzed by Jacob Viner (1950), the establishment of a free trade area or a custom union would give rise to trade creation effect 
FIGURE 1. Revenue Trlangle of Tax Revenue

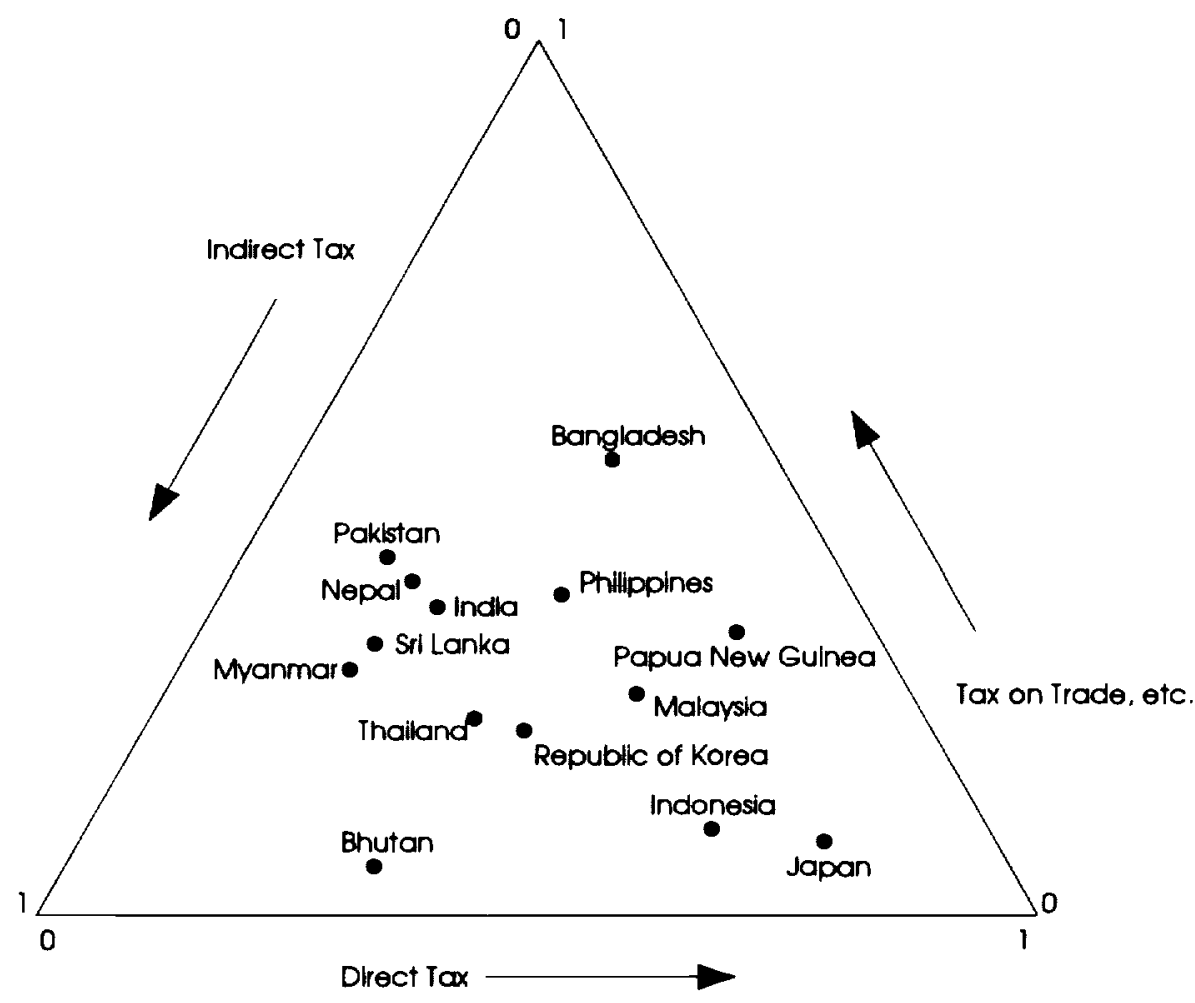

Source: Hamada (1995). 
within the union, but to trade diversion effect to outside the union. If the trade diversion effects are too strong, Asian countries worry, economic vitality of Asian nations may be considerably impaired.

There are two movements, at least, towards economic integration in Asian regions. One is the East Asian Economic Caucus (EAEC) and another Asian Pacific Economic Cooperation (APEC). The EAEC is led by the initiative of Premier Mahathir of Malaysia. He proposes that the ASEAN countries and East Asian nations such as Korea, Japan, Taiwan, should create an economic community of more or less strong economic ties. The United States does not like the Asian integration which excludes her. Japan, because of her heavy dependence on the United states in trade, has a ambivalent position. To date the most recent news is that Japan will not join the EAEC.

By the U.S. initiative, and perhaps by Japan's implicit suggestion, the APEC was created in 1989 as an economic cooperation all over the Pacific Economic Basin. It is a loose type of economic integration all over the Pacific including United States, Canada, Mexico, and all the Asian and West Pacific countries including New Zealand and Australia. It is not clear what kind of economic integration the APEC will bring forth. If it proceeds, then the United states is at the same time a member of the NAFTA that is a formal free trade area and a member of the APEC that is presumably weaker, but nevertheless solid integrated area. 
The purpose of this paper is to assess the economic conditions for Asian countries to cope with the situation where EU and NAFTA are formed. The questions are whether it is desirable for them to form its own trading area. If desirable, is it better to have a closed one like the EAEC or a more open one like the APEC. In order to analyze these questions, we rely on public economics and strategic consideration that clarifies the rational incentives for nations to participate or not to participate in an economic union, or other economic cooperation.

In Section II and III we present two related but different types of models on tariffs and trade. In section II, we analyze a model of symmetric nations (or symmetric groups of nations) that produce differentiated products under increasing returns to scale and monopolistic competition. There is a group of nations which decide whether or not to be united into a free trade area. We study the incentive problem in it. In section III, we also consider a trade model with differentiated products under increasing returns to scale and monopolistic competition. We vary, however, the sizes and the number of countries and show that properties of the Nash equilibrium depends on the number of countries, the relative size of countries, and in particular the relative size of the leading country, namely, the hegemon. In any case the non-cooperative Nash equilibrium usually divert from the Pareto optimal configuration.

In section IV, we would like to analyze the calculus of participation given strategy to play with tariff policy. In 
other words we ask how your country will be motivated to join in the regional agreement or coalition. In section $v$, we come back to reality and in the light of these theories ask what is the incentive structure concerning the counter actions to regionalism in Europe and the North America and concerning the formation of EAEC and APEC.

\section{Implications of a Symmetric Tariff Bloc Model}

We would like to briefly summarize the results of GotoHamada (1995) that studies the symmetric world with differentiated product with increasing returns and monopolistic competition.

Suppose there are four symmetrical countries or four symmetrical groups of countries that produce differentiated product with increasing returns, namely with fixed cost. Accordingly, monopolistic competition prevails as market structure. This is a variant of the new trade models that have been studied by Dixit, Krugman, Lancaster and many others extensively. For a more detailed formal model of the analysis in this section, see Appendix I of this paper. Using the model presented in Appendix I, we compared the welfare level of each of the four countries in the following three stages, in order to understand the incentive-theoretic political economy of regional economic integration in Asia and the Pacific:

\section{STAGE 1: Before Integration}

In this original stage, the four countries engage in 
trade with each other, and all imported products are subject to the same tariff rate $t$.

\section{STAGE 2: Initial Integration}

In this second stage, country 1 and country 2 are integrated and there are no tariffs on the trade between the two countries. But, country 3 and country 4 are still separated. Therefore, the trade of country 3 and 4 with FTA countries as well as the trade between country 3 and country 4 are subject to the original tariff rate $t$.

\section{STAGE 3: Counter-Integration (Two Polar Blocs)}

As will become clearer in the following analysis, country 3 and country 4 are worse off after the integration of country 1 and country 2 , and there is an incentive that country 3 and country 4 form a counter bloc (e.g, the Mahatir Plan after EC92 and NAFTA in the real world). In this third stage, country 1 and country 2 form an economic bloc while country 3 and 4 form another economic bloc. The trade within the bloc is subject to no tariff while trade between blocs is subject to the same common external tariffs $(t)$.

We start, after using the simplification of constant elasticity of demand, the world where four regions are independent and not forming a free trade area and levy an identical tariff rate to the outside regions (STAGE 1). A region is either a country or a group of countries within which trade is 
free.

Four regions are trading with each other with levying a constant tariff rate. With the simplification used by Krugman that the elasticity of demand for each differentiated product can be regarded as a constant, production decision is predetermined by technology regardless of the value of tariffs. Note that, as Krugman and many others, we assume a large number of $\mathbf{N}$ and therefore neglect the second term of denominator of equation (5) in the Appendix I. Therefore, the number of types of differentiated products and the elasticity of substitution among them do not change before and after the integration. In other words, while the model captures a terms of trade effect, it does not capture a possible positive effect of the regional integration resulting from more exploitation of increasing returns to scale technology. Trade is beneficial because it allows the consumption of the more balanced composition of differentiated goods. In the future study, we will investigate the issue more thoroughly by incorporating variable elasticity as well as the change in terms of trade.

The role of tariff rates is thus to give preferential price to the domestic products and, after integration, the product of other countries in the free trade area to which a particular country belongs. Consumers prefer consuming as evenly as possible both domestic and foreign products. However, because foreign products are under tariffs they are compelled to consume more domestic (or within region) goods than foreign goods. The 
unevenness in consumption created by tariff rates is the cost of protection. And the balanced consumption basket for differentiated products is the source of the gains of trade. In this setting, suppose two regions are united without changing tariff rates towards goods from outside the bloc (STAGE 2). Then this will give preferential treatment to the region that is in the same tariff bloc. Therefore, the regions in the integrated area will gain by trade creation effect. However, those who were excluded from the integrated area will suffer from the trade diversion effect. More trade will take place within the integrated area, so that other countries will find it more difficult to compete with goods in the region. We found out with a given tariff rate an integration of two countries will never fail to give negative impacts on the rest-of-the-world countries that are left behind.

The impact of regional integration on the welfare level based on the formal model shown in the Appendix I is summarized in Table 2. While we omit the proof due to the limitation of the space (for those who are interested in the proof, see Goto-Hamada (1995)), Note that the unambiguous results in Table 2 do not depend on the parameter values of the model.

Article 24 of the GATT stipulates that countries who are uniting to a customs union or a free trade area should not raise tariff. From the results we described above, however, Article 24 is not good enough as a safeguard against the loss generated by a free trade area to the rest of the world. 
Then for the rest of the world incentives emerge to unite themselves to create a custom union or a free trade area. After this countervailing integration, the symmetric structure of two integrated areas each of which have two regions will be restored (STAGE 3). The situation of the rest of the world improves and the situation of the first free trade area deteriorates from the position they obtained when other countries are not integrated. This will be an incentive, and possibly be a justification for Asia to be integrated to form their own FTA.

Needless to say, when the four countries form a single union (or when the totally free trade prevails in the world), the welfare level of each country becomes higher than that under Stage 3. In this sense, we cannot advocate that Asian countries hould form their own countervailing trading bloc based on the conclusion of the above analysis. Instead, the above analysis merely suggests that the welfare of Asian countries is higher when they form a countervailing FTA than when they are left behind from any trading blocs. Since the analysis using the model predicts that the welfare of Asian countries will increase even more if they are united with the Western Hemisphere as well as with each other, the APEC which includes countries of both sides of the Pacific ocean as its member countries seems to be a promising alternative. 
TABLE 2

WELFARE IMPLICATION OF REGIONAL INTEGRAIION

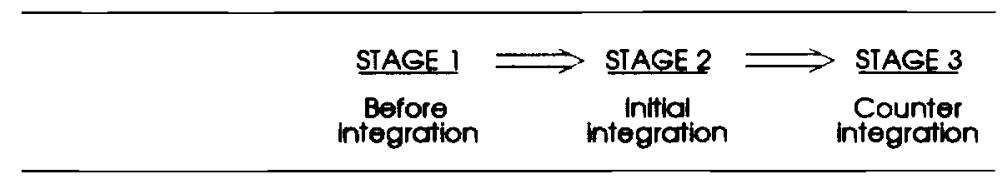

1. Ierms of Irade

Countries $1 \& 2$

Countries $3 \& 4$
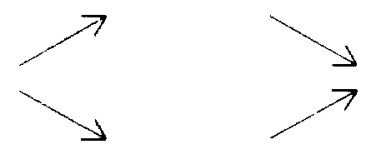

2. Welfare

Countries $1 \& 2$

Countries $3 \& 4$
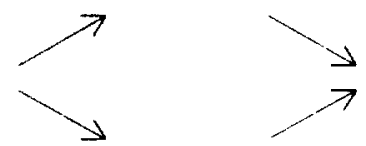

Source: See Goto and Hamada (1995) for details. 
III. The optimal Tariffs and the Relative size of Regions

In the above model, the size of each region is identical, and the level of the tariff rate is constant. Of course, depending on the relative size of the free trade area, motivations of regions to join an integration are affected. Also they normally choose the most desirable tariff rates that also depends on the relative size of a region.

We do not think that this is the place to develop all the mathematics of the optimal tariffs and retaliation process, but in order to convey the reader the idea of what is involved we would like to sketch the results that are obtained by Gros (1987) and interpreted by Krugman (1991). The question is what is the optimal tariff structure in the world where differentiated goods are produced under increasing returns and monopolistic competition. In other words, what are the reaction curve of a region given the other regions' tariff rates? This question is solved by Gros and then a simplified derivation was developed by Krugman in such a way as to be applied to economic integration. Krugman (1991) and stein (1994) consider the effect of dividing the whole world into various blocs of equal sizes, and ask the question of the optimal number of symmetric blocs. Instead, in this section, we consider the world where the relative size of a bloc is variable, and ask the question of incentives for each country or region to create or join a bloc. We believe that this approach is at least complementary to, and even more realistic than their approach. 
Then, consider the case that the world is divided into two blocs, each of which does not have the identical size. Then we can derive a formula of optimal tariff rate of bloc I with respect to a given tariff rate of bloc II (Gros, 1987). The tariff rate of the home country is non-zero even though the country is infinitesimally small. This reflects the product differentiation and monopolistic competition assumed in the new trade model.

On the other hand, the optimal tariff is a decreasing function of tariff rate of the trading partner and an increasing function of the relative size of the home country. In order to understand the role of monopolistic or monopsonistic power by tariffs of countries that differ in their sizes, a formal model is presented in Appendix II. While, to make the point as clear as possible, Appendix II present a Ricardian model of trade, readers who are familiar with trade theory will easily understand that similar properties to those to be obtained in the appendix will hold to the Hechscher-ohlin model with variable factor proportion. It can be shown that a similar conclusion can be extended to an increasing returns to scale model with monopolistic competition.

In our model with a large country (a hegemon) and a small country (or countries) summarized in the appendix, the implication of the sizes of countries is obvious. In short, in international trade with tariffs as policy instrument, the hegemon has a capability to manipulate the terms of trade for her 
advantage. Therefore, it is optimal for a larger bloc to impose a higher tariff rate. Thus if they engage in tariff war, the larger bloc gains more by imposing a high tariff. The great exploits the small!

One can extend this analysis to the case of many-country world where a group of countries with many participants will find it more profitable to put high tariff rate. If economic integration proceeds, there is an incentive for a group of nations like EU or NAFTA to impose a higher rate of tariff. Article 24 of the GATT would work against this. The article is a safeguard agreement to prevent such monopolistic behavior. Our results in section II indicate that just keeping the tariff rate unraised could still be harmful for the rest of the world.

Consider a situation where a larger country and many small countries impose minimum level of tariff, but a larger country can choose to react in such a way that she can be the von stackelberg leader. The country would create a larger and larger free trade area. Incentive-wise the larger group will find it more profitable to impose an optimal tariff. GATT 24 prohibits this, but the analysis of the last section would mean that in spite of this GATT provision it would be profitable for countries to unite. Of course, this process cannot go all the way. If there is hardly any other country remaining in the rest of the world, then the optimal tariff may not yield any gain because there is hardly any party to exploit. so at some point the process should stop. In such a world where all the nations are 
united except Monaco, there is nothing to exploit from Monaco, whatever optimal tariff they charge.

\section{The calculus of Participation}

We would like to apply the calculus of participation to the formation of free trade area. The calculus of participation, sometimes called the theory of clubs, takes the decision of a nation as a rational decision facing various alternatives and constraints. Nations are supposed to calculate whether or not to join in a coalition or a group considering the national cost and the benefit by joining a coalition or a group.

The incentive problem of forming or joining an economic union can be analyzed from the standpoint of calculus of participation. Olson (1965) has developed an analysis of collective action, but the analysis is of limited significance to cooperation in economic integration because it assumes a predetermined membership. Buchanan (1964) has developed an economic theory of clubs that allows for variable size of membership. Although his analysis is directed mainly at the problem of efficiency rather than the political structure of conflict, it provides a useful tool for analyzing collective action with variable members.

As indicated in Hamada (1985), international economic relations can be characterized as a two-stage game. The first stage requires agreeing on a system or rule, and the second involves the interplay of economic policies under a given rule. 
The second stage is analogous to the prisoner's dilemma; the first is analogous to the battle of the sexes.

Recently in the theory of participation, the tools of public economics have been applied to political science, providing the theoretical basis for associating group behavior with individual rationality ${ }^{2}$.

The rational theory of participation (see, for example, Riker and ordeshook 1973, chapter 3) indicates that an individual decision unit decides to participate in a collective action if the anticipated benefit is larger than the cost. The rational decision for a country contemplating membership in an economic union is to join if the benefits from participation are larger than the costs.

When the benefits of collective action exhibit a public-good character, however, the amount of collective action may be less than optimal, where optimality is judged by the Paretian standard. Olson showed this by applying the theory of public goods to collective action (Olson 1965; Olson and Zeckhauser 1966). Suppose there is a single public good whose benefits are commonly shared by participating agents. The rational decision by an individual agent is to equate the marginal private benefit from the public goods to the marginal cost of supplying a unit of the public good. However, the optimal outcome from the point of

${ }^{2}$ The application of tools developed in economics to politics requires caution, but recent developments in political science have shown that the application of economic analysis can clarify the political analysis of economic conflicts. 
view of society as a whole is to equate the marginal cost to the social benefit, which is the sum of the individual benefits. Thus, the supply of public goods may be less than optimal because the individual decision unit does not take account of the external effect on other decision units. Therefore, even when a consensus exists concerning the objective of a collective action, the amount produced may be too small. The interesting testable hypothesis about group behavior is that the behavior of a large group will be different from that of a small group; the shortfall in supply will be more likely the larger is the group because the free-rider problem intrinsic in the supply of public goods without the possibility of exclusion will be more acute if each member shares in the common benefit to only a small degree. A second hypothesis is that the decision unit that receives a relatively large proportion of the benefit of public goods will be likely to bear more than a proportional share of the cost. In other words if each participant behaves rationally according to the private benefit-cost calculation, a small decision unit can exploit a large one.

The same argument can be applied to the analysis of public "bads" as well. If costs are incurred in preventing the generation of public bads, then there is a tendency to overproduce public bads, inasmuch as the marginal social harm of public bads is larger than their marginal private harm. olson's theory of collective action, interesting as it is, is subject to several criticisms. First, as pointed out by 
Wagner (1966) and developed in more detail by Frohlich, Oppenheimer, and Young (1971), the theory of collective action neglects the role of political entrepreneurship or leadership in integrating the individual benefits to a collective action. If an agent with political entrepreneurship can persuade the group of the effectiveness of collective action in spite of the apparent excess of individual cost over individual benefit, then the proper amount of collective goods may be supplied, with some leadership surplus being left over for that agent.

second, the analysis assumes passive behavior on the part of each participant and accordingly neglects the leader-follower relationship analyzed in von stackelberg (1934). If a participant picks the most profitable point on the opponent's reaction curve, then he behaves as a leader and can enjoy the leadership or exploitation solution. (To avoid complication arising from the two uses of the word leadership, this case will be called exploitation, while leadership in the sense of political entrepreneurship will be called political entrepreneurship).

An economic theory of clubs with variable size of group and with possible exclusion of nonmembers from enjoyment of the collective goods has been developed by Buchanan (1964). According to his analysis, collective goods are supplied optimally provided that appropriate charges are imposed on the use of the service and provided that the services of the collective goods can be exclusively supplied to the member of the 
group. This approach has more relevance to monetary integration since the benefits of integration are public in that their enjoyment by a particular member does not diminish the enjoyment of others but at the same time most of the benefits are enjoyed almost exclusively by the countries participating in the monetary union. In short, there exists nonrivalry in the consumption of the services of a monetary union but not nonexclusiveness.

The decision of countries considering whether to participate is based on a comparison of the gains from joining a union with the costs. The resulting implication is straightforward: If there are externalities in increasing the size of membership, an individual nation's participation decision based on a rational calculation may lead to a smaller than optimal economic union even if the country is fully aware of the costs and benefits. The problem is that an individual nation's decision is based on a private benefit-cost calculation, while the public benefit to the group as a whole includes the gains to the countries that are already in the union.

In the case of a free trade area (FTA), a nation decide whether or not to form a FTA (or to join an existing FTA) by comparing the benefits with the costs. In this tariff case, however, the common tariff is the public good. In other words, the joint consumption good is the optimal tariff for the coalition to the rest of the world countries. What are the costs to them? There can be costs in political dimension that we will go into later, but aside from them, the sacrifice is not so 
expensive because small countries cannot effectively retaliate.

Therefore, the common tariff will be the optimal tariff from the point of view of the union. The results would be that, each country would like to extend the free trade area until some point where you cannot increase the exploitation of the others.

On the other hand, if tariff is restricted by GATT Article 24, one cannot go further enough to reach the optimal size of dominating union. You have to stop somewhere before that. Thus, GATT Article 24 has a function to keep countries from creating an extraordinarily large free trade area because the tariff strategy is 1 imited by Article 24 .

So far, we were concerned with the situation where the national interest is united. But, it is sometimes difficult to agree on "the national interest". And there is a need to consider the effect of domestic conflicts and sectoral opposition to the formation of a free trade area. In the NAFTA, the labor union in the United states opposed to a creation of a free trade area. In developing countries, many sectors oppose to joining a free trade area because import competing industries fear the loss of profit due to foreign competition without tariff protection. Therefore, even in the world where one can impose the optimal tariff for national advantage, still there will be opposition from labor unions and various sectors against a free trade area. When a nation cannot choose the optimal tariff, then there will be more problem for the movement against the free trade area. In this case it may obstruct the international trade, but 
at the same time it will block the formation of a large free trade areas that will exploit the rest of the world by its monopolistic power. These discussions are related to the hegemonic stability theory, a favorite topic of political scientists. The incentives of small countries and the incentive of hegemon can be analyzed from this type of analysis. The solution differs very much between the case where monopolistic power of trade is concerned and the case where the creation of common public goods is involved. In the former case of private goods, the large exploit the small, while, in the case of public goods, the small exploit the large.

Ideally, the calculus of participation should be able to predict the dynamic process of formation of coalitions among countries. We know what happens if the world is divided into some regions, what is the effect of integrating several countries (or region) to a country. We do not know well why a group of nations emerges as an economic region, and how the process of integration evolves. N-person game theory gives only a partial one. In order to answer these questions, we probably need a multi-dimensional approach incorporating geography, military relations in addition to economic factors.

\section{The Future of Asian Community}

From these discussions the following observations on the Asian situation will emerge.

First, the EAEC by the leadership of Malaysia can be 
considered as a natural response of Asian countries against two big blocs in the world, EU and NAFTA. It is natural that Americans do not like this move because a formation of economic block in Asia will have a negative economic impact on the nonAsian countries. But we do not exactly understand why many Americans show such an emotional attitude towards this proposal as claiming that the proposal is racial, anti Caucasian, and economically vague. Premier Mahathir contributed a letter appealing to the readers of the Yomiuri, the largest newspaper in Japan, that questions why Americans allow Europeans to create a common market and not Asians. This argument was quite persuasive.

Second, it is natural for the United States to have opposing coalitions like the APEC to nullify the possible economic impact of the EAEC. The APEC is supported by Japan as well. At the moment Japan is leaning towards the decision not to join the EAEC. The Japanese economy is interwoven very closely by way of trade and foreign investment with the U.S. economy. Even though in recent years Japan's trade with Asia surpassed the trade with the United States, the trade tie between Japan and the U.S. is strong.

Therefore, although the wishes of some Japanese is to go "out of the West to Asia," as opposed to the motto of the Meiji Restoration period, "out of Asia to the West", the Japanese are obliged to remain ambiguous. Because of the Japanese ambivalence and the American persistence to be meddlesome the world over, the 
APEC is established to make Asian Pacific a vast region as a big economic community with yet to be specified probably loose economic integration.

This attitude of the United States gives us an impression of the declining hegemon. In more objective terms, however, we should also note that the APEC has a different structure than the NAFTA or the EU. The United states is inside the NAFTA and at the same time she intends to be under the same umbrella that cover all the Asia Pacific countries. It gives the set of integration a rhizome rather than tree structure so to speak. Therefore, if we may take an optimistic view, through the United states the tightness of the NAFTA trade bloc may be broken as a wind vent, and there may be some possibility of creating a superimposed regional integration of the American continent and the Pacific ocean.

Thus compared with the situation where Asia creates an independent trading bloc and counteracts with the EU and the NAFTA, the American acquisitive attitude and a loose structure of the APEC may yield a result that is beneficial to the American and the Pacific region. 3 Perhaps the APEC is a way towards international free trade.

${ }^{3}$ This is a natural conclusion of our analysis in section II. Namely, in the world of four countries (or regions), the welfare level of each country is higher when all four countries unite together into a single union than when there are two polar blocs. 
Goto/Hamada

Appendix I: A Symmetric Tariff Bloc Model

This appendix briefly summarize the symmetric tariff bloc model of Goto-Hamada (1995).4

In the model, consumers of a representative country $k$ $(k=1,2,3,4)$ possess the following individualistic social utility function $\left(\mathrm{U}_{\mathrm{k}}\right)$.

(1) $\mathrm{U}_{\mathrm{k}}=\left\{\sum_{i=1}^{\mathrm{N}} \mathrm{C}_{\mathrm{ik}}{ }^{\beta}\right\}^{1 / \beta}, \quad 0<\beta<1$,

where $c_{i k}$ is the amount of consumption of the $i$-th differentiated product in country $k$, and $N$ is the number of types of differentiated products available to consumers. Consumers maximize their utility subject to the budget constraint (2).

$$
\text { (2) } \sum_{i=1}^{N} P_{i k} C_{i k}=Y_{k} \text {, }
$$

where $P_{i k}$ is the domestic price (i.e., tariff-inclusive price) of the $i$-th differentiated product in country $k$, and $Y_{k}$ is the national income of country $k$.

From the above utility maximization problem, we obtain the following inverse demand functions.

$$
\text { (3) } P_{i k}=c_{i k}^{\beta-1} y_{k} / z_{k} \text {, }
$$

where

4 While the basic model developed in Goto-Hamada (1995) can incorporate any number of countries, differences in country size, and, to some extent, asymmetric tariff, the model in this appendix is a simplified version which assumes four identical countries and symmetric tariff. 
(4) $z_{k}=\sum_{i=1}^{N} c_{i k}^{\beta}$.

From (3) the elasticity of demand for the i-th differentiated product $\left(\epsilon_{i k}\right)$ is

(5) $\epsilon_{i k}=\frac{1}{(1-\beta)+\beta C_{i k}^{\beta} / Z_{k}}$.

If we assume a large number of $\mathrm{N}$ and the symmetry of each differentiated product, as Krugman (1979) and Dixit and Norman (1980) did, we can simplify the problem, e.g. (5) reduces to the following.

$(5)^{\prime} \epsilon=1 /(1-\beta)$.

Note that we now omit the subscript $i$ and $k$ for $\epsilon$ because the demand elasticity of the products turns out to be the same for all products due to the symmetry assumption.

The producer of the $i$-th differentiated product in country $k$ is characterized by the following cost function.

(6) $\quad T C_{i k}=W_{k} F+W_{k} m\left(\Sigma C_{j=1}^{4}\right)$,

where $T C_{i k}$ and $W_{k}$ are total cost of the $i-t h$ producer and wage rate in country $k$, respectively. $m$ is the labor input requirement per unit of output, while $F$ is a fixed amount of factor input necessary for any positive amount of production. The producer maximizes the following profit function (7).

$$
\text { (7) } \pi_{i}=\sum_{j=1}^{4} \frac{1}{1+t_{j}} P_{i j} c_{i j}-w_{k} F-w_{k} \underset{j=1}{\operatorname{m}\left(\sum c_{i j}\right),}
$$

where $\pi_{i}$ is the profit of the $i-t h$ producer and $t_{j}$ is the tariff 
rate imposed by country $j$ on the imported differentiated product. Note that, due to the assumption of a symmetric tariff, $t_{j}$ is the same for all $j$, except for the case of $j=k$. Needless to say, there are no tariffs imposed on the domestic goods. From the profit maximization problem, we obtain the following profit maximizing price for the $i-t h$ producer in country $k$, as shown in equation (8). Note that, without the loss of generality, country $k$ is assumed to produce the first $n_{k}$ types of differentiated products.

(8) $\quad P_{i j}=w_{k} m\left(1+t_{j}\right) / \beta$.

Further, we assume free entry and free exit. Therefore, profit of each existing firm is forced to zero. Hence, equation (9) holds in equilibrium.

$$
\text { (9) } \pi_{i}=\sum_{j=1}^{4} \frac{1}{1+t_{j}} P_{i j} c_{i j}-w_{k} F-w_{k} m\left(\sum_{j=1}^{4} c_{i j}\right)=0 \text {. }
$$

The demand for labor by the $i$-th producer $\left(l_{i}\right)$ is obtained.

$$
\text { (10) } \quad 1_{i}=F+m \sum_{j=1}^{4} c_{i j}
$$

The domestic labor supply is assumed to be constant, i.e., there is no wage-leisure trade-off. Therefore, the sum of labor input in all firms in country $k$ is equal to the amount of the domestic labor supply in that country (L).

$$
\text { (11) } \sum_{i=1}^{n_{k}} 1_{i}=L
$$

where $n_{k}$ is the number of firms in country $k$.

The tariff revenue accrued to the government is assumed to 
be distributed to domestic consumers in a lump-sum fashion. since there is no profit in equilibrium, the national income consists of factor payment and tariff revenue.

(12) $w_{k} L+\sum_{i=n_{k+1}}^{N} \frac{t_{k}}{1+t_{k}} P_{i k} c_{i k}=Y_{k}$

where $t_{k}$ is the tariff rate imposed by country $k$ on her imports.

The above model is complete, and the above specification gives equilibrium conditions for a representative country $k$. We can solve the model, once the values of parameters $\left(m, F, \beta, t_{k}\right.$ ' L) are identified.

Using the above model, we compared the welfare level of the three stages discussed in the main text, (i) before integration, (ii) initial integration, and (iii) counter integration. While we omit the proof due to the limitation of the space (for those who are interested in the proof, see Goto-Hamada(1995)), using the above model, we can rigorously show the pattern of the welfare change shown in Table 2 . 
Appendix II: The size of Countries in a Model of Tariffs

Let us start from a two-country situation of the Ricardian model where labor is the only factor of production. To produce two goods 1 and 2 , the larger country (hegemon) has input coefficients $a_{1}, a_{2}$, and the smaller country has input coefficients $a_{1}{ }^{*}, a_{2}{ }^{*}$. The larger country has a comparative advantage in producing good 1 so that $a_{1} / a_{2}<a_{1}{ }^{*} / a_{2}{ }^{\star}$. The two countries have labor endowment $L$ and $L^{*}$, and the larger country is large enough to warrant $\max \left(L / a_{1}, L / a_{2}\right)>\max \left(L^{*} / a_{1}{ }^{*}, L^{*} / a_{2}{ }^{*}\right)$.

The utility function of a representative consumer is expressed as a function of per capita consumption $c_{1}, c_{2}$, and $c_{1}{ }^{*}, c_{2}{ }^{*}$ as $U\left(c_{1}, c_{2}\right)$ and $U\left(c_{1}{ }^{*}, c_{2}{ }^{*}\right)$. Both governments are assumed to conduct their tariff policies in such a way to maximize the utility of the representative consumer.

Then the offer curves are drawn as in the following Figures. Figure $A-1$ indicates the case where hegemon is so large that the smaller country's offer curve intersects with that of the hegemon on the straight line (with slope $a_{1} / a_{2}$ ) through the origin. Then the smaller country satisfies the definition of a "small country" and thus cannot take advantage of the elasticity of the hegemon. The hegemon can impose an optimal tariff to exploit its monopolistic power in exports, or monopsonistic power in imports, in such a way to make her trade indifference curve tangent to the offer curve of the smaller country, that is at $T$.

If the size of the smaller country is very small, the gain in terms of trade does not bring substantial welfare gain because 
the amount of trade is limited (See point $S$ in Figure $\mathrm{A}-2$ ). Unless the smaller country is capable of exercising its monopolistic (monopsonistic) power, the gain from tariff is larger if the smaller country occupies some space in the world economy (See point $M$ ).

Now we can relax our two country assumption. Suppose there are one hegemon and $n$ smaller countries. Figure A-3 illustrates the case with $n=2$. since there is no incentive for smaller countries to become stackelberg leaders as long as they cannot change the terms of trade offered by the hegemon, the same point as $M$ will be enjoyed by the hegemon, smaller countries are both left at point $s$.

We can depict the strategic situation by reaction curves in the space of the tariff rate of the hegemon $t$ and that of the smaller country (or countries) $t^{*}$ (Figure A-4). In this Ricardian situation the reaction curve of the smaller country (or countries) coincides with the horizontal axis. The reaction curve of the hegemon starts with the optimal tariff $\hat{E}$ in the absence of retaliation upward. Therefore the Nash solution $\mathrm{N}$ is the combination $(\hat{E}, 0)$, which is coincides with the von stackelberg solution with the hegemon as the leader. The smaller country (or countries) does not have incentives to be a leader. We all know that when the two (or more than two) countries have similar size, then more complex situations emerge in which a tariff by a single country triggers retaliation by the other, and in which each country strives to be a von stackelberg leader. 
In our model with a hegemon and a small country (or small countries), the implication of the sizes of countries is obvious. In short, in trade of goods situation with tariffs as instruments, the hegemon has capability to manipulates the terms of trade for her advantage. In the Heckscher-ohlin model with variable factor proportion, there is no longer a linear segment in the offer curve. However, since the large country has an almost linear segment so that our results will apply without significant modification. 
FIGURE A-I

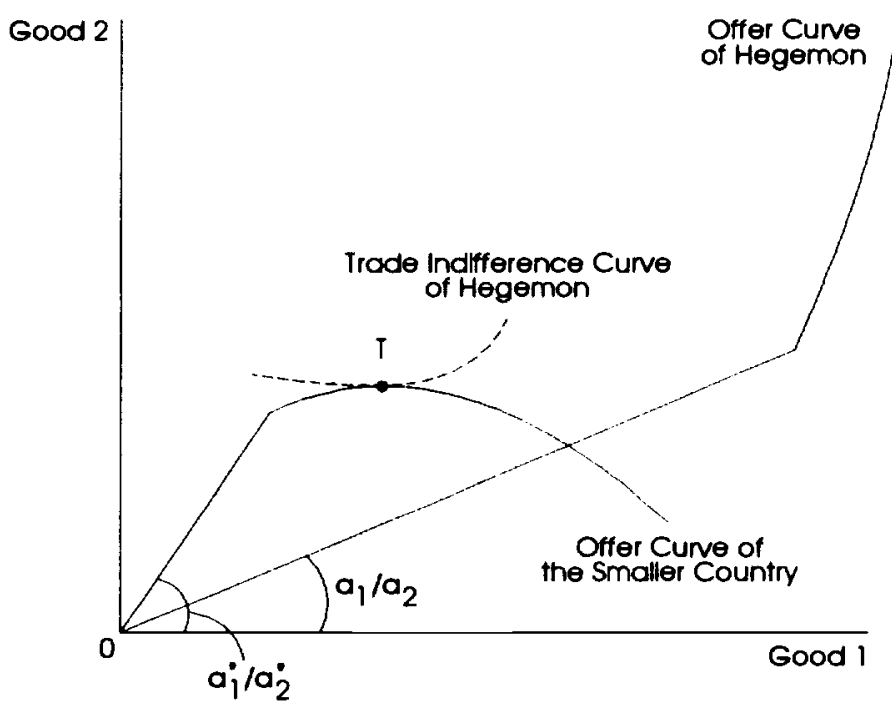

FIGURE A-2

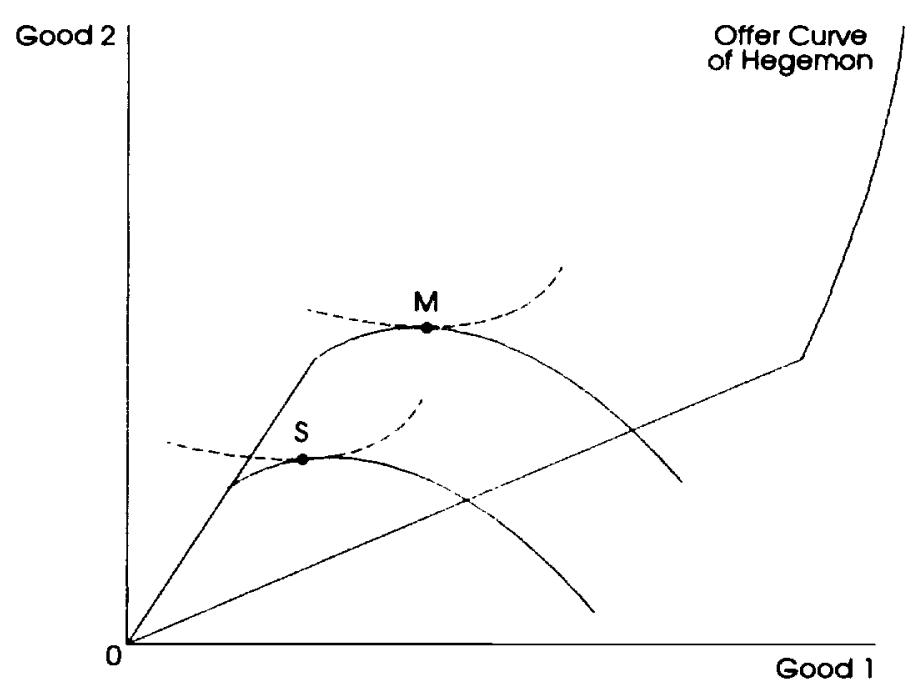


FIGURE A-3

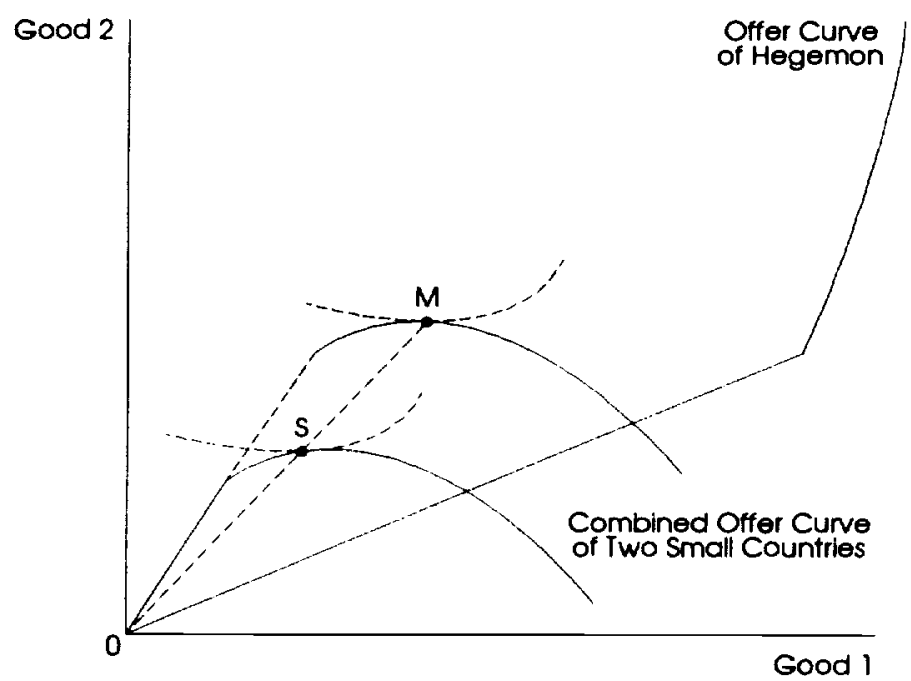

FIGURE A-4

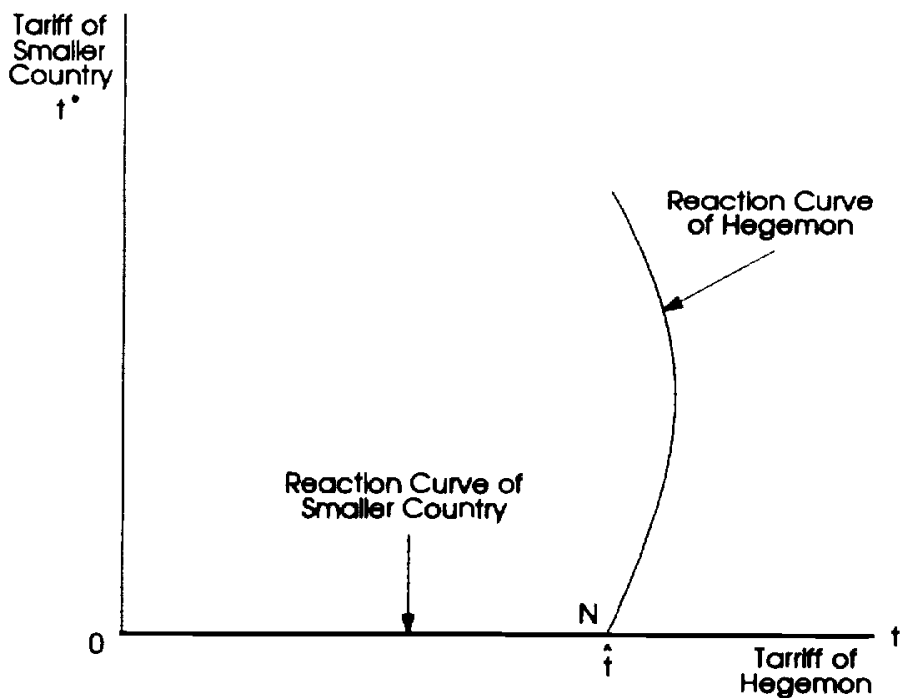




\section{REFERENCES}

Buchanan,J.M. (1964), "An Economic Theory of Clubs", Economica, Vol.32.

Frohlich, N., J.A. Oppenheimer, and O.R. Young (1971), Political Leadership and Collective Goods, Princeton, NJ: Princeton University Press.

Goto, Junichi and Koichi Hamada (1994), "Economic Preconditions for Asian Regional Integration", in T. Ito and A. Krueger (eds.) Macro Economic Linkage, Chicago: The University of Chicago Press.

Goto, Junichi and Koichi Hamada (1995), "Economic Integration and the Welfare of Those Who are Left Behind: An Asian Perspective" paper presented at the AEA Annual Meeting in Washington, DC.

Gros, Daniel (1987), "A Note on the Optimal Tariff, Retaliation and the Welfare Loss From Tariff Wars in a Framework with Intra-Industry Trade", Journal of International Economics, Vol.23, pp. 357-367.

Hamada, Koichi (1985), The Political Economy of International Monetary Interdependence, Cambridge, MA: MIT Press 
Krugman, Paul (1991), "Is Bilateralism Bad?", in E. Helpman and A. Razin (eds.) International Trade Policy, Cambridge, MA: MIT Press.

Morishima, Michio (1982), Why Has Japan 'Succeeded'? Western Technology and the Japanese Ethos, London: Cambridge University Press.

Nomura Research Institute (1989), Nomura Medium-Term Economic outlook for Japan and the World, Tokyo.

Olson, M., Jr. (1965), The Logic of Collective Action: Public Goods and Theory of Groups, Cambridge, MA: Harvard University Press.

Riker, W.H., and P.C. Ordeshook (1973), An Introduction to Positive Political Theory, Englewood Cliffs, NJ: PrenticeHall.

Srinivasan, T.N. (1994), "Regional Trading Arrangements and Beyond: Exploring Some options for South Asia", The World Ban, South Asia Region Report (\#IDP-142).

Stein, Ernesto (1994), Essays on the Welfare Implications of Trading Blocs with Transport costs and on Political cycles of Inflation, unpublished Ph.D. dissertation. 
von Stackelberg, H. (1934), Marktform und Gleichgewicht, Vienna: Julius springer.

Wagner, R.E. (1966), "Pressure Groups and Political Entrepreneurs: A Review Article," Papers on Non-Market Decision Making 1. 